\title{
Developments and Applications of Carbon Nanotube Reinforced Cement-Based Composites as Functional Building Materials
}

\author{
Kai Cui ${ }^{1,2}$, Jun Chang ${ }^{2 *}$, Luciano Feo ${ }^{3}$, Cheuk Lun Chow ${ }^{1}$ and Denvid Lau ${ }^{1 *}$ \\ ${ }^{1}$ Department of Architecture and Civil Engineering, City University of Hong Kong, Hong Kong SAR, China, ${ }^{2}$ School of Civil \\ Engineering, Dalian University of Technology, Dalian, China, ${ }^{3}$ Department of Civil Engineering, University of Salerno, Fisciano, Italy
}

Carbon nanotube (CNT) is a promising nanomaterial with excellent mechanical, electrical, thermal, and chemical stability. It has received extensive attention due to its unique multifunctional properties in engineering materials. Researchers have explored the preparation and characterization of CNT reinforced cement-based materials. Studies have shown that adding CNT will significantly improve the performance of cement-

OPEN ACCESS

Edited by:

Yu-Fei Wu,

RMIT University, Australia

Reviewed by:

Sekhar Chandra Ray,

University of South Africa, South Africa

Antonella D'Alessandro,

University of Perugia, Italy

*Correspondence:

Denvid Lau

denvid.lau@cityu.edu.hk

Jun Chang

mlchang@dlut.edu.cn

Specialty section: This article was submitted to

Structural Materials,

a section of the journal

Frontiers in Materials

Received: 24 January 2022 Accepted: 22 February 2022

Published: 08 March 2022

Citation:

Cui K, Chang J, Feo L, Chow CL and Lau D (2022) Developments and Applications of Carbon Nanotube Reinforced Cement-Based Composites as Functional Building Materials.

Front. Mater. 9:861646. doi: 10.3389/fmats.2022.861646 based materials. This article introduces the techniques for the dispersion characterization of CNT and summarizes the advantages and disadvantages of these techniques. The functionalized applications of CNT in cement-based materials are reviewed, including sensing performance, structural health monitoring of concrete, electromagnetic shielding, and other applications. In addition, the application and development prospects of CNT in 3D printing concrete have been prospected. Finally, we discussed the existing problems and challenges in developing and applying CNT in cement-based materials and suggested future research.

Keywords: carbon nanotube, application, functional properties, structural health monitoring, 3D printing concrete

\section{INTRODUCTION}

Concrete is a widely used building material in the construction field, with low cost and stable performance. Concrete consists of cement, aggregate, and water. After contact with water, a hydration reaction forms a cementitious material. The cementitious material combines the fine aggregate and the coarse aggregate and effectively transfers the compressive load to the stronger aggregate throughout the entire mixture. It makes concrete a durable and economical building material (Sheikh et al., 2021). The most important properties of concrete materials include compressive strength and flexural strength, toughness, rigidity, and ductility. However, ordinary concrete has low mechanical performance, less toughness, easy cracking, and poor durability, which reduces the service life of the concrete and severely limits material development. In overcoming these shortcomings and preparing high-strength, high-toughness cement-based materials, fibers of different scales have attracted widespread attention. Each fiber has its strengthening and toughening mechanism. The mechanism is related to the fiber's shape, content, size, and surface structure (Chang et al., 2020; Cui et al., 2021; Ramezani et al., 2022). The service life of civil engineering infrastructure can be as long as dozens or even hundreds of years. Many structural damage problems start from minor defects. During long-term application, load fatigue effects and natural disaster erosion will cause a considerable accumulation of structural damage, eventually 
destroying the structure. If the damage is not discovered and is instead ignored, these defects will evolve into serious problems, endangering the usability and safety of the structure, which can easily lead to catastrophic emergencies and cause significant property and personnel losses. It is essential to perceive the service status of concrete structures in real-time to provide early warning, repair, and control damage in critical situations. The destruction of concrete starts with micro-nano cracks, developed into macroscopic cracks, and finally, the concrete fails. It is vital to prevent and delay the development of micro-nano cracks early by implementing crack detection techniques. Therefore, structural health monitoring (SHM) of concrete is essential; it has attracted extensive attention worldwide. Traditional SHM has achieved great success, but conventional sensors have poor durability, high construction requirements, and poor material compatibility, limiting their wide application in concrete materials. The emergence of selfsensing cement-based materials provides a new idea for selfsensing sensors, which can effectively overcome the shortcomings of traditional sensors.

In the past 2 decades, the application of smart concrete with self-sensing ability in the infrastructure SHM system has been extensively developed. The self-sensing ability of concrete is achieved by a change in the conductive network of the conductive material inside the concrete (Al-Dahawi et al., 2016a; Al-Dahawi et al., 2016b; Al-Dahawi et al., 2017; Yıldırım et al., 2018; Demircilioğlu et al., 2019; Yıldırım et al., 2020). Smart concrete is developed by adding carbon nanotube (Xing et al., 2016; Al-Dahawi et al., 2017; Gupta et al., 2017; Yoo et al., 2017; Yildirim et al., 2018; Lee et al., 2020; Yildirım et al., 2020), carbon fibers (Al-Dahawi et al., 2017; Y1ldırım et al., 2018; Yildırım et al., 2020), steel fibers (Le and Kim, 2017; Demircilioglu et al., 2020; Le and Kim, 2020), graphite nanofibers (Yoo et al., 2017), graphene (Al-Dahawi et al., 2016a; Al-Dahawi et al., 2016b; Al-Dahawi et al., 2017; Yoo et al., 2017; Birgin et al., 2020; Wang et al., 2020), nickel or hybrid materials (Azhari and Banthia, 2012; Konsta-Gdoutos and Aza, 2014) and other functional fillers. The research on CNT reinforced self-sensing cement-based materials is the most concentrated. The Young's modulus and tensile strength of CNT can reach up to $1 \mathrm{TPa}$ and $200 \mathrm{GPa}$. It also has an excellent absorbing function and can be used as an electromagnetic shielding material. It can enhance durability and electrical conductivity. Most importantly, $\mathrm{CNT}$ can be used as a self-sensing material for monitoring concrete health.

Summarizing the research papers of the past 10 years, researchers have explored the performance of CNT reinforced cement-based materials. CNT achieves enhancement effects through nucleation, improving pore structure, and controlling nanoscale cracks. It has the potential to provide a new generation of multifunctional cement-based materials. However, there are several significant challenges; CNT has particular physical and chemical properties, the issue of whether these properties can be successfully transferred to materials depends mainly on CNT - the state of dispersion in the matrix. Because CNT has a strong tendency to agglomerate, obtaining a uniform carbon nanotube dispersion is highly challenging. There is also the scalability issue for obtaining higher well-dispersed CNTs. There are many methods for this dispersion, including physical and chemical methods. However, there is no unified standard or specification for CNT dispersion, which limits the standardized use of CNT in building materials. There is an urgent need to summarize the shortcomings of different dispersion technologies for CNT to provide a reference for formulating a unified dispersion standard. The current research mainly focuses on macroscopic performance, and the research content is mainly concentrated at the laboratory level. Related research is still in its infancy in terms of functional application. There is an urgent to have further in-depth study, theoretically and practically.

In this review, we summarized the research progress of CNT in the practical application of building materials. First, the commonly used techniques for the dispersion characterization of CNT are introduced, and the advantages and disadvantages of these techniques are summarized. The effects of different influencing Factors on the functional application of CNT in cement-based materials are then discussed. The functional applications of CNT in cement-based materials are reviewed, including sensing performance, SHM, and electromagnetic shielding. In addition, the application and development prospects of CNT in $3 \mathrm{D}$ printing concrete (3DPC) have been prospected. CNT is expected to become a potential 3DPC material. Using $\mathrm{CNT}$ in $3 \mathrm{DPC}$ can effectively reduce the latter's setting time and improve production efficiency. It can also reduce the drying shrinkage of $3 \mathrm{DPC}$, enhance printing quality, and improve 3DPC's early strength. Finally, the challenges faced when developing and applying CNT reinforced cement-based materials are summarized.

\section{PRETREATMENT OF CARBON NANOTUBE}

CNT can be uniformly dispersed is crucial when applying CNT in cement-based materials (Assi et al., 2021). Due to the large surface area, large aspect ratio, and strong van der Waals force of CNT, it is easy to agglomerate, making it difficult to disperse uniformly in cement-based materials. CNT dispersion is defined as the separation of a single multi-walled carbon nanotube from its filling body and the maintenance of the separated multi-walled CNT to achieve uniform distribution in the cement matrix (Vaisman et al., 2006). Researchers have proposed various dispersion techniques; there are two main types of methods. The first approach is physical methods such as ultrasonic, mechanical stirring, and ball milling. Ultrasound provides energy to overcome van der Waals interaction. Ball milling can smash the agglomeration of carbon nanotube caused by van der Waals force, but it will reduce the aspect ratio of CNT and reduce its role in the matrix (Singh et al., 2013); mechanical stirring includes manual and magnetic stirring, usually combined with the ultrasonic method (Ubertini et al., 2014). The second type is a chemical method to disperse CNT by improving the wettability of its surface, usually by adding covalent bonds or non-covalent bonds and by adding functional hydroxyl and carboxyl groups on the surface of the CNT (Li et al., 2005). 


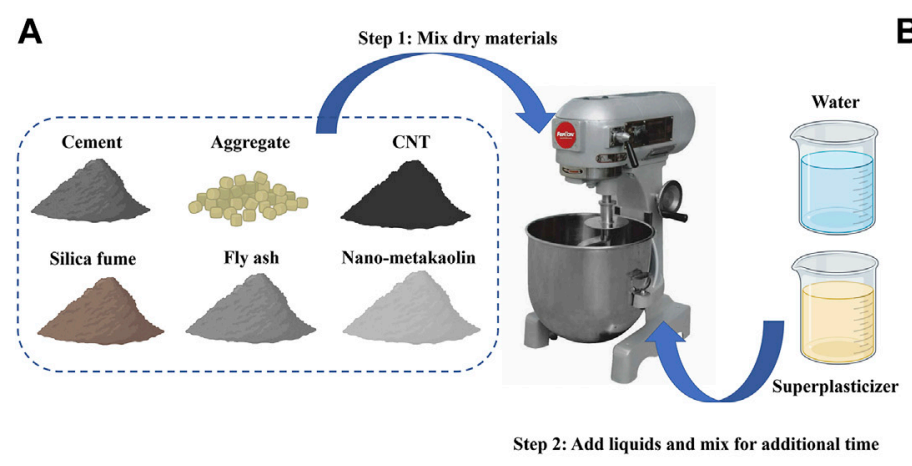

B

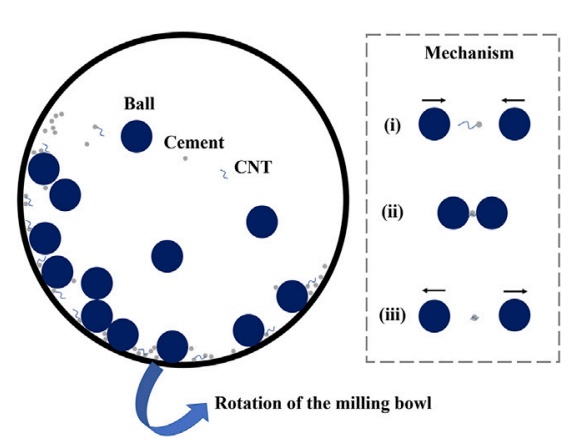

FIGURE 1 | Procedure of CNT dispersion: (A) dry mixing, (B) ball milling.

Figure 1 illustrates a schematic procedure for dry mixing and ball milling.

\section{Physical Dispersion Technology}

Researchers used ultrasonic probes to disperse CNT. At present, there is no specific specification or standard for the research of ultrasonic dispersion of CNT. This ultrasonic dispersion depends on the ultrasonic time, temperature, energy, type of ultrasonic device, and CNT concentration. Ultrasonic treatment is necessary to disperse CNT; the dispersion created by ultrasonic treatment exhibited an inverse relationship with time (Shi et al., 2019). Ultrasound time is significant for the dispersion of CNT. Longterm ultrasound can cause damage and fracture to CNT, while the CNT cannot be uniformly dispersed if the ultrasound time is too short. The ultrasonically dispersed CNT regroups together after extending the standing time to form agglomerates (Mendoza et al., 2014). Therefore, it is necessary to add corresponding surfactants to improve the dispersion effect. The surfactant is wrapped or adsorbed on the surface of the CNT during ultrasonic action. Therefore, this method neither destroys the structure of the CNT nor reduces the mechanical properties. However, when several types of surfactants were used, the surfactants were incompatible with the hydration products of cement, resulting in the slow hydration process of cement. Surfactants are divided into two types: ionic and nonionic. The amphiphilic molecules of ionic surfactants can be adsorbed on the surface of CNT and coated. The hydrophobic chain can adsorb CNT in its structure, and the hydrophilic group can form electrostatic repulsion in the polar solution molecules to disperse the agglomerated fibers. The nonionic surfactant has a strong interaction with the p-p bond of CNT; therefore, it can encapsulate the surface of CNT, reduce the van der Waals force between the tubes, and achieve the purpose of dispersing CNT (Mendoza et al., 2014).

There are three types of typical surfactants, cationic surfactants, including Cetyl trimethyl ammonium bromide $(\mathrm{CTAB})$ and dodecyl trimethylammonium bromide (DTAB); anionic surfactants, including sodium dodecyl sulfate (SDS), sodium dodecylbenzene sulfonate (SDBS), Gum Arabic (GA), Poly-naphthalene sulfonate sodium salt, and dodecyl-benzene sodium sulfonate (NaDDBS); and nonionic surfactants including
Triton X-100 (TX10), propylene glycol aliphatic ether (SR), and polyoxyethylene lauryl ether (Brij35). Our commonly used surfactants are GA, SDS, and PAAP, which play a definitive role in the required duration time for attaining a homogenous dispersion (Sobolkina et al., 2012). For example, it is reported that when GA is used as the coating surface of CNT, a GA concentration of $0.45 \mathrm{~g} / \mathrm{L}$ has the best dispersion effect (Wang et al., 2013a). There are also studies using a superplasticizer as a dispersant. After adding a polycarboxylate superplasticizer, the dispersion degree of CNT is improved, and the exothermic heat of the hydration reaction is delayed (MacLeod et al., 2021). When PVP is used as a dispersant, the ultrasonic step significantly impacts CNT dispersion. There are studies on using multi-step dispersion of CNT, including ultrasonic energy for high-energy pre-dispersion and then unhydrated cement particles for lowenergy dispersion. The CNT, after dispersion, can bridge the cracks, fill the pores, and refine the pore size of the C-S-H matrix (Chen and Akono, 2020). Some researchers have quantitatively studied the effect of different concentrations of anionic and nonionic surfactants on the deaggregation of CNT. When the ratio of CNT to surfactants is 1:1-1:1.5, and the ultrasonic time is $120 \mathrm{~min}$, the best dispersion effect for CNT is achieved. After combination with the surfactant Brij35, the deaggregation effect of CNT is pronounced for nitrogen-doped CNT. The use of SDS as a surfactant has a negative impact on strength because foam is formed during the mixing of the cement paste. Some researchers have compared the dispersion effects of several surfactants, including SLSD, SDS, TX-100, GA, and CTB. After 1 hour of ultrasound, the dispersion effects are SLSD, SDS, GA, CTB, TX100 (Sindu and Sasmal, 2017). Researchers have developed a novel DDA dispersant with the similar physical and mechanical performance of cementitious materials and enhanced electrical properties (D'Alessandro et al., 2021). Figure 2 shows the unzipping mechanism.

\section{Chemical Dispersion Technology}

In many studies, surfactants have been used to disperse CNT in water to achieve efficient dispersion in cement-based materials (Mendoza et al., 2014). However, there are some problems; for instance, different surfactants are not compatible with water, 


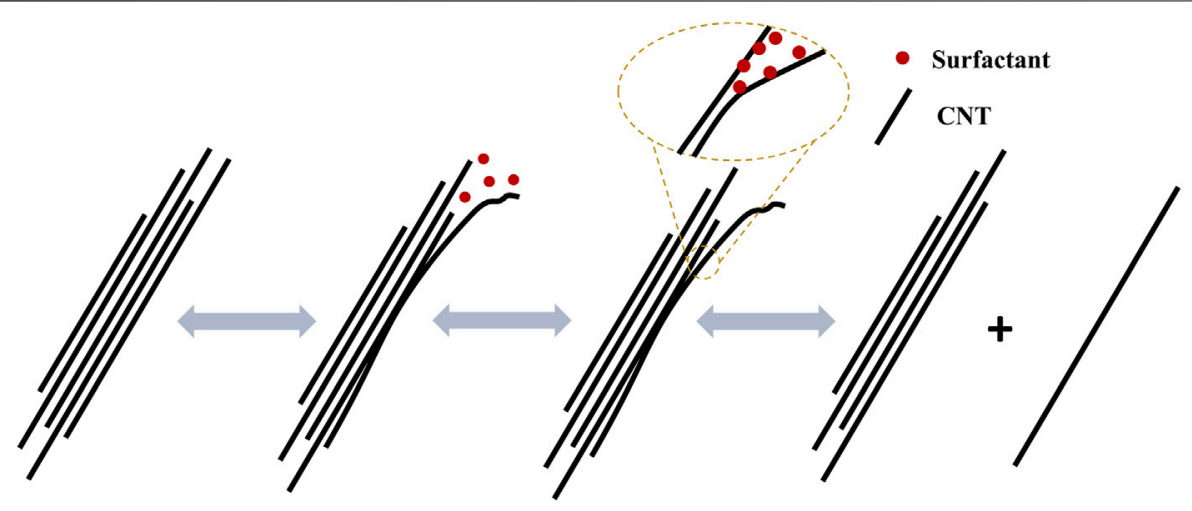

FIGURE 2 | Unzipping mechanism under the effect of the surfactant.

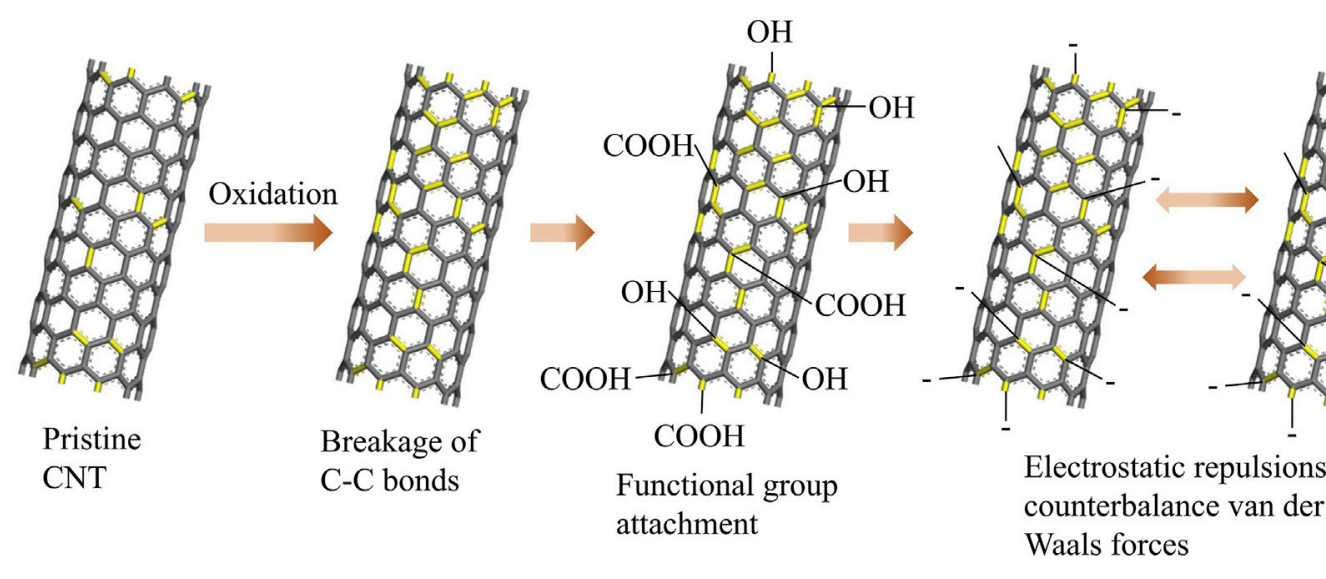

FIGURE 3 | Acid-etching mechanism

which may also reduce the hydration progress of cement. Therefore, many researchers have improved the dispersion of CNT by changing the hydrophilicity of the CNT body; it is called covalent functionalization (Shi et al., 2019). The chemical functionalization method is achieved by modifying the atomic structure of CNT. Covalent bonds are formed between the surface of CNT and functional groups, usually in the form of three operating groups: 1) hydrocarbon group; 2) halogen; and 3) oxygen. The introduction of functional groups on the surface of CNT through covalent chemical modification improves the dispersibility of carbon nanomaterials in the cement matrix. It reacts with $\mathrm{C}-\mathrm{S}-\mathrm{H}$ and $\mathrm{C}-\mathrm{H}$ bonded firmly between the cement matrix and fibers. Commonly used methods include acid etching or oxidation. Usually, after strong acid etching, functional groups will be coupled to the surface of CNT, which enhances its hydrophilicity and improves its dispersibility (Yu et al., 2008; Elkashef et al., 2016; Li et al., 2020).

Mixed sulfuric acid and nitric acid solutions are commonly used to treat CNT. Many factors affect the acid etching technology, including the concentration of CNT, amount of acid, ultrasonic method, temperature, energy, duration, and sequence of steps. Studies have shown that the degree of functionalization of CNT depends on the sulfuric acid and nitric acid ratio (Datsyuk et al., 2008). Nitric acid is used to attach functional groups to disturbances/defects on the surface of CNT. The sulfuric acid changes the surface morphology of the carbon nanotube (forming surface roughness), which leads to yields of different functional groups (i.e., different degrees of oxidation). There has been a considerable amount of research on the covalent functionalization of CNT. Figure 3 illustrates acidetching in the CNT mechanism.

\section{SUMMARY OF CNT PRE-MIXING PREPARATION}

Summarizing the existing literature, we found that researchers have drawn similar conclusions about CNT dispersion technology and opposite conclusions. Some researchers believe that sole surfactants and ultrasound are essential to disperse CNT. Others use a mixture of multiple surfactants, considering that the amount of surfactant is different and that the optimal ultrasound duration varies from person to person. Some researchers believe that CNT has hydration activity and can undergo hydration 
reactions with cement. However, other researchers believe that CNT has no hydration activity and cannot undergo hydration reactions with hydration products. Therefore, a covalently functionalized dispersion technology has been introduced to promote the combination of CNT and hydration products. Some researchers combined covalent functionalization and ultrasound to disperse CNT, and some directly used covalent functionalization to disperse CNT. In addition, it is necessary to study the effect of surfactants on cement and CNT. Although the current dispersion method has proved to be very effective for CNT, does the use of surfactants have a negative effect on the performance of cement and CNT? What is the specific impact? The answer to whether it will affect the cement hydration process and reduce the performance of cement-based materials while improving the dispersibility is unknown, and researchers need to conduct detailed studies. In short, there are no unified standards for the dispersion of CNT. There is an urgent need to establish such unified standards and specifications. The technology of CNT reinforced cement-based materials must adapt to advanced characterization technologies in other fields and strictly apply the technology used in traditional cement-based materials. Understanding these nanoscale interactions and scale relationships will bring the benefits of nanoscale to the macroscale. We should unify standards for the effectiveness and performance of carbon nanotube composites; specific test standardization development will help develop carbon nanotube cement technology.

\section{SMART PROPERTIES}

Many factors affected the smart properties during the preparation and application of CNT reinforced functional cement-based materials, such as curing age, relative humidity, temperature, electrode arrangement, and resistivity measurement methods. This section will discuss the influence mechanism and improvement measures of the above factors in detail.

\section{CNT Content}

One of the core factors affecting the perceived performance of cement-based materials is the CNT content, which determines the distribution of the conductive network inside the materials. It has been confirmed that too high a CNT content will reduce the sensing ability of the composite material and aggregate in the matrix, increase the cracks inside it, and affect its density. Poor dispersion of CNT can also have a detrimental effect on performance because it increases the resistivity of the composite material. The results showed that the agglomeration of CNT improved the resistivity of the material (Kim et al., 2014a). Of course, within a reasonable dosage range, the resistivity of the composite material decreased along with the increase in CNT content. Studies have found that when CNT reinforced composite materials' volume fraction of CNT increases from 0.5 to $1 \%$, the decrease in resistivity becomes the most significant. For example, compared with the resistivity of composite material with 1 vol\% CNT, composite material with 0.5 vol\% CNT is reduced by about $94 \%$ at the same age (Yoo et al.,
2019). Of course, there are also contrasting experimental results. Some studies have found that lower filler content (0.05\%) shows a minor increase in resistivity and gradually increases compared with higher filler content ( 0.1 and $0.3 \%$ ), which indicates that the pores are uniform throughout the matrix distribution (Sasmal et al., 2017).

\section{Temperature and Curing Time}

$\mathrm{CNT}$ can improve the high-temperature resistance of cementbased materials. One study explored the influence of CNT reinforced cement-based materials at high temperatures and found that the addition of CNT improved strength more than in ordinary concrete (Baloch et al., 2018). The influence on the resistivity signal of CNT composites is continuous or gradual, while the effect of dynamic load on the resistivity signal of CNT composites is instantaneous and abrupt. Therefore, the former can filter out interfering signals without affecting the detection accuracy of the sensor.

The temperature has an important influence on the resistivity of the composite material, showing positive and negative effects (Monteiro et al., 2017). The microstructure and macroscopic properties of cement-based materials influence each other. As the curing age increases, the microstructure of the matrix becomes dense, the porosity decrease, and the relative resistivity of the matrix increases along with the hydration degree (Liu et al., 2013). The hydration degree increases with the extension of the curing age; more hydration products are generated, filling the pores of the matrix, and the matrix becomes denser. The conductive path and resistivity inside the matrix also change along with the porosity of the matrix, which affects the perception performance (Galao et al., 2014; Yildirim et al., 2015). The resistivity increases along with the curing time. The matrix becomes denser; the porosity decreases, making ion conduction difficult, and the resistivity increases. Early on, due to a low degree of hydration, the moisture of the matrix contains many ions, and the composite material has a high porosity. Therefore, ion conduction is easy to undertake and is significant in cement-based materials (Sun et al., 2002). The resistivity increases along with the curing time (Yildirim et al., 2015). As the curing age increases, CNT improves the performance of the composite material through pore filling, bridging, and a denser $\mathrm{C}-\mathrm{S}-\mathrm{H}$ structure; this significantly increases the conductivity of the matrix (Jung et al., 2020a; Jung et al., 2020b).

\section{Relative Humidity}

There are three main conductive paths for self-sensing cementbased composites. In a typical self-sensing composite material, when the content of conductive material reaches a critical value, the formation of the percolation network of conductive material causes the resistivity of the composite material to drop sharply, showing a power-law downward trend (Zhou et al., 2020). The effect of water content in seepage pores is a critical factor that must be considered. Among them, ionic conductivity is easily affected by the water content of the matrix. In the case of a small amount of conductive material, ionic conductivity plays a crucial role in resistivity. The moisture content inside the cement-based 
material changes along with the ambient humidity, which affects the conductive path and sensing performance. The resistivity of the composite material changes with the change of water content, and the changing trend is closely related to the type of conductive material. For CNT reinforced cementitious materials, the resistivity decreases with water content (Wen and Chung, 2006). The effect of moisture content on resistivity is also related to the content of conductive fillers. The type and content of conductive fillers greatly influence the water content of self-sensing cement-based composites in terms of their sensing properties. Some scholars have studied the effect of moisture absorption in CNT reinforced cement-based composite samples, using oven-dried samples with CNT content of $0.1,0.3$, and $0.5 \%$. The results show that the decrease in FCER percentage is smaller than conventional concrete in the fully saturated state, while the $0.5 \%$ CNT reinforced cement-based materials increase the FCER by 75 and $80 \%$ in the partially saturated and dry state, respectively (Siad et al., 2018). Therefore, it can be concluded that moisture reduces the sensitivity of the self-perceived properties of CNT reinforced cement-based materials.

\section{Other Influencing Factors}

Other factors that affect the sensing performance include the geometry of the CNT, the corrosive environment, the distance between the electrodes, the size effect of the specimen, the creep of the material under long-term load, and freeze-thaw cycles. The mechanism needs to be further studied. The electrodes are arranged, and the resistivity measurement method is an essential factor affecting measurement accuracy. In terms of the number of electrodes, the four-electrode process can effectively reduce the contact resistance between the electrodes and the substrate and improve the accuracy of the results. The twoelectrode method for resistivity measurement is only recommended when the small sensor volume. In terms of the electrode arrangement, the resistance measured by the surfacebonded electrode is more significant than that measured by the embedded electrode because the implanted electrode has good contact with the conductive filler, which reduces the contact resistance (Han et al., 2020). The geometry of CNT affects the distribution and conduction mechanism of the conductive network in cement-based materials. Several studies have researched the geometry of CNT in terms of sensing sensitivity (Malekzadeh and Zarei, 2014; Eftekhari et al., 2020). It has been shown that the fracture energies of specimens increase significantly with the addition of longer CNT with similar volume fractions (Sethi et al., 2017). In addition, the crack propagation of long CNT reinforced concrete specimens is lower at the same loading level (Eftekhari et al., 2014). The resistivity of CNT reinforced cementbased materials will be significantly reduced in corrosive environments, which will reduce the self-sensing ability of the composite. When the distance between the electrodes changes, the internal resistance increases along with the separation between electrodes. Studies have shown that increasing the distance between electrodes leads to increased resistance and decreased output. It has also been found that the greater the distance between electrodes, the higher the resistance (D Alessandro et al., 2015).

\section{APPLICATIONS}

\section{Piezoresistive Sensor}

Piezoresistive sensors monitor the resistance change of the sensor under external pressure to evaluate this pressure (Kim et al., 2017a; Chen J. et al., 2019). In some cases, when the sensor supplies a constant current, the voltage is monitored to assess the externally applied force. These sensors can detect traffic flow and speed and assess the number and weight of vehicles passing along the road. At the same time, sensors are influenced by environmental effects such as vehicle loads of several tons, temperature, and humidity. Therefore, the sensors must have remarkable performance and durability (Nam et al., 2016). For ordinary building structures, self-sensing cement-based materials can be made into small sensor elements and embedded. CNT reinforced cement-based materials can be applied in SHM, including roads, railways, and buildings. Cement-based piezoresistive sensors include carbon black, graphite, carbon fiber, and carbon filament; these carbon-based materials often require modification on their surface or use of dispersion agents such as methylcellulose and silica fume. Researchers have extensively studied the piezoresistive properties of conductive cementitious composites (Azhari and Banthia, 2012; Galao et al., 2014; García-Macías et al., 2017; Le and Kim, 2020). Some researchers have fabricated a new self-sensing cement-based composite sensor; the sensor has excellent application prospects in structural model recognition and SHM, while the sensing signal needs to be further optimized (Ding et al., 2020). The sensor will affect the signal during long-term use due to polarization effects. Determining the damage location of the structure is conducive to timely repair. By installing multiple new sensors, the location of the damage can be determined (Baeza et al., 2013), and it becomes convenient to repair the structure. One study embedded multiple sensors in concrete and determined the damage site by analyzing the resistivity change of each sensor (D Alessandro et al., 2017). Some researchers have proposed that CNT reinforced cement-based materials could replace ordinary concrete and be used on railway sleepers (Jing et al., 2021). Others have developed a data acquisition system for sleepers, which can measure the dynamic load of passing trains. Some scholars have proposed a new CNT reinforced cement-based materials technology application for SHM. Impact hammer tests with reinforced beams have been used to compare the results recorded by the CNT composites with strain gauges, with the overall results showing that the CNT composite sensor is promising for identifying natural frequencies. Some researchers have explored cement-based sensors for monitoring the dynamic behavior of concrete members under loading. The results show that the input-output of the model has a specific nonlinear relationship (Materazzi et al., 2013).

\section{Electromagnetic Wave Shielding and Absorbing Material}

Electromagnetic (EM) shielding refers to various conductive materials that reflect electromagnetic waves. The primary mechanism involves the reflection of electromagnetic waves in 


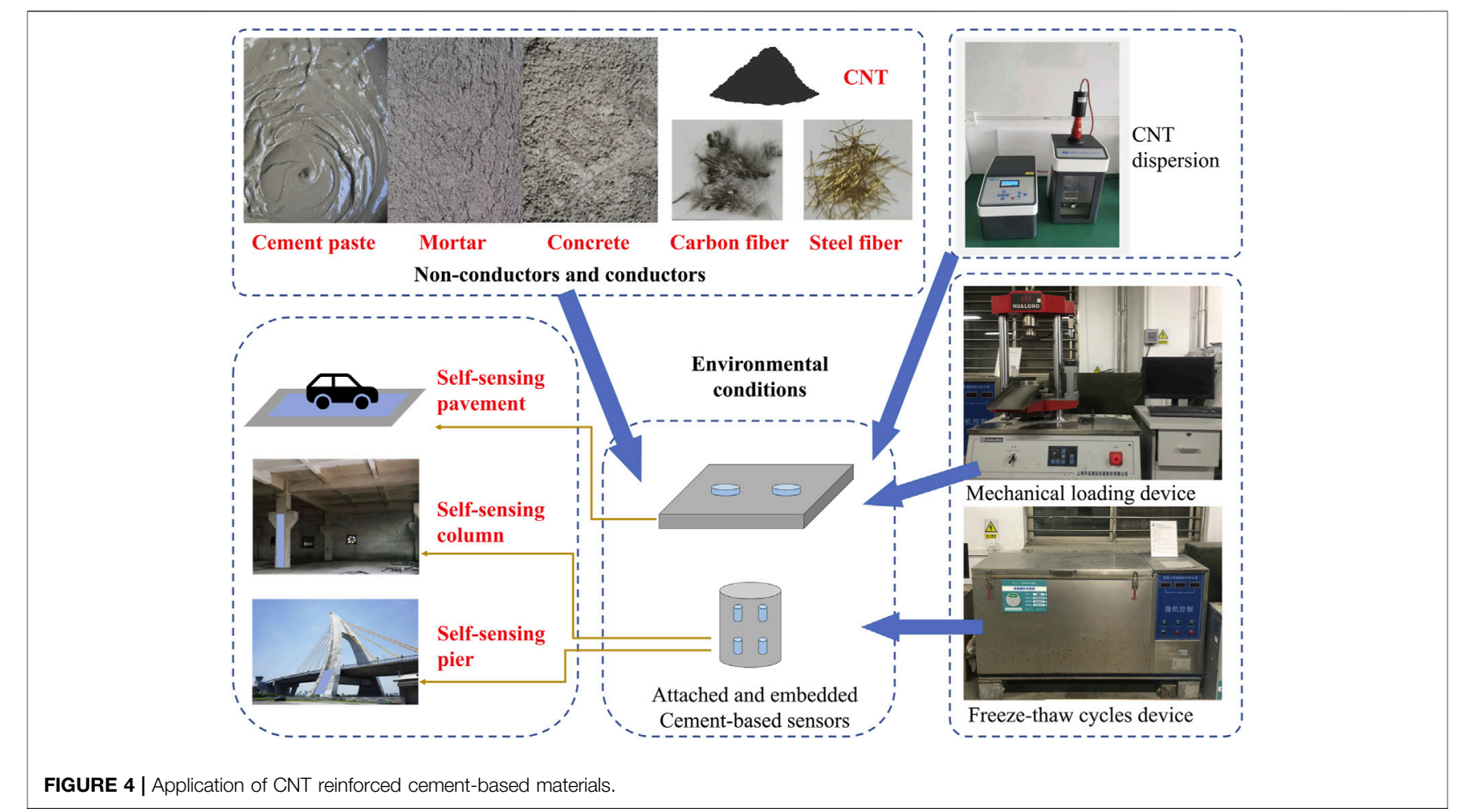

the direction of penetration or transmission, absorption within the shielding material, and dissipation as heat (Nam et al., 2011). EM interference caused by electromagnetic wave radiation affects the operation of electronic equipment and the human body. It can damage foundations and security (GRAYSON, 1996; Szmigielski, 1996). Therefore, the absorption and shielding of electromagnetic waves are becoming more and more critical in the field of construction. CNT reinforced the performance of cementbased materials (Konsta-Gdoutos et al., 2010; Xu et al., 2015; $\mathrm{Xu}$ et al., 2019) and endowed them with innovative functions (Kim et al., 2014b; Kim et al., 2016; Kim et al., 2017b), including electromagnetic wave shielding/absorbing properties (Nam et al., 2018).

Various studies on the CNT enhanced Electromagnetic interference and shielding effectiveness (EMI SE) of cementbased composites have been carried out (Micheli et al., 2014). Therefore, researchers have conducted a series of studies on the EMI SE of cement composites mixed with CNT and found that improving the electrical conductivity of cement composites is a crucial factor in enhancing the EMI SE of cement composites (Yoon et al., 2021). Due to its extremely high electrical conductivity, CNT is increasingly used in many composite materials for SE. The results for most of the composites containing multi-walled CNT suggest that these composites have promising applications in electromagnetic interference shielding. Therefore, improving the volume fraction of CNT increases the overall SE of the composite. However, one of the crucial limiting factors of CNT as filler material for composites is its highly high fabrication cost (Wanasinghe et al., 2020). The researchers have explored various factors on the absorbing properties of CNT. They studied the dielectric parameters through waveguide measurements in the $0.75-1.12 \mathrm{GHz}$ frequency band, currently used in mobile phone radio access networks. The obtained results can calculate the electromagnetic shielding effectiveness of large-scale wall-shaped concrete structures. When the CNT inclusions were increased to $3 \mathrm{wt} . \%$, the shielding effect of the $15 \mathrm{~cm}$ thick wall reached $50 \mathrm{~dB}$. The researchers studied the wave-absorbing properties of CNT cement composites. The effects of CNT content and sample thickness on electromagnetic wave reflectivity were discussed in the frequency range of $2-8 \mathrm{GHz}$ and $8-18 \mathrm{GHz}$. When the CNT content is $0.6 \mathrm{wt} . \%$, a cement mortar sample with a thickness of $25 \mathrm{~mm}$ has a remarkable ability to absorb electromagnetic waves close to the absorption peak in the frequency range of $2-8 \mathrm{GHz}$ (Wang et al., 2013b). Figure 4 shows the application of CNT reinforced cement-based materials.

\section{D Printing Concrete}

With the development of urbanization and industrialization, the shortage of labor resources in current society, low production efficiency, and safety problems have restricted the development of the construction industry (Noorvand et al., 2013; Hosseini et al., 2014; Ye et al., 2017). The development of 3D printing concrete (3DPC) technology has provided an efficient construction method for the entire construction industry. 3D printing (3DP), also known as additive manufacturing, uses a computer to draw 3D data models and then print out components of various shapes. The process involves printing layer after layer to build the intended product. In 1981, Kodama invented the prototype of 3DP. Since then, 3DP has developed rapidly and has 
been widely used in many industrial fields, including the fabrication of complex structures and objects, medical items (Seol et al., 2014), and food manufacturing (Sun et al., 2015). $3 \mathrm{DPC}$ is a type that can be deposited layer by layer by a 3D printer without any formwork support and vibration process. With further development and application, 3DP could revolutionize manufacturing in the future; it has already expanded into architecture and construction. Previous studies have shown that 3DPC technology construction can reduce construction waste by $30-60 \%$, labor costs by $50-80 \%$, and production time by $50-70 \%$. Compared with traditional construction technology, 3DPC has the advantages of high construction efficiency, high degree of mechanization, high degree of automation, low labor cost, freedom of $3 \mathrm{D}$ printing construction, and less construction waste (Ma et al., 2018a; Asprone et al., 2018; Buswell et al., 2018; Ngo et al., 2018).

Therefore, the research and application of 3DPC are of great significance in civil engineering. 3DPC has been developed along with the development of 3DP technology. 3DP technology has high requirements for the performance of $3 \mathrm{DP}$ materials, including good workability, excellent performance, and adjustable setting time. The printing parameters and different materials can adjust for these. Researchers have investigated the workability (Le et al., 2012a; Perrot et al., 2016; Hambach and Volkmer, 2017; Ma and Wang, 2018; Soltan and Li, 2018) and performance (Gibbons et al., 2010; Le et al., 2012b; Feng et al., 2015; Gosselin et al., 2016; Panda et al., 2017a; Panda et al., 2017b; Al-Qutaifi et al., 2018; Panda et al., 2018; Tay et al., 2019) of 3DPC and explored the relationship between the two (Kazemian et al., 2017; Ma et al., 2018b).

3DPC differs from conventional concrete in rheology, printability, and mechanical properties. Although the advantages of $3 \mathrm{DP}$ include the freedom to customize printing and design, some disadvantages also limit the development of 3DP. These disadvantages include high cost, few practical engineering applications, lack of engineering experience, poor mechanical properties and anisotropy, materials, and defects. One of the main disadvantages of 3DP is the formation of voids between subsequent layers of material. Poor adhesion between different printed layers of 3DPC leads to high porosity, which reduces its performance. The degree of porosity formation is highly dependent on the 3DP method and printing material. The construction of voids is widespread and is considered one of the primary defects leading to poor mechanical properties and anisotropy. We can add different fibers to reduce the porosity of cement-based materials.

It has been reported that researchers typically use nanofillers and viscosity modifiers to provide the rheological requirements required for 3DPC (Panda et al., 2019). It is well known that in 3DPC mixes (Khan, 2020), the printability is improved by using a large amount of cement, which results in higher heat for its hydration of cement (Snelson et al., 2008), leading to drying shrinkage and blocked nozzles. When the amount of cement is lower, the setting time of 3DPC is longer, the early strength is low, and the printability is low. Therefore, the researchers recommend the addition of mineral additives in 3DPC mixes. The use of coarse aggregate due to the small diameter of the nozzle is considered to be another reason for the increased risk of drying shrinkage. In 3DPC blends, researchers suggest adding fibers to the mix to reduce this shrinkage (Ye et al., 2021; Yu et al., 2021). Considering these effects, it can be seen that material type and quantity are critical for 3DPC.

For successful 3D printing of concrete, it has dual rheological properties. On the one hand, the material should be sufficiently fluid to be pumped and extruded, mainly influenced by mix ratio and material selection. On the other hand, the material should be solid and rigid enough to maintain its shape and withstand its own and above-layer weight. The higher the concrete viscosity, the lower the yield stress, the more excellent the plasticity, and the better the workability. For 3DPC, we need to solve the problems from the following aspects: 1) reducing the heat of hydration and setting time of 3DPC, 2) improving the early strength, 3) reducing the shrinkage deformation of 3DPC. Studies have shown that the addition of admixtures improves the workability of the 3DPC mixture, which reduces the extrusion process and improves print quality. The study found that viscosity modifiers can improve the shape stability after extrusion and improve the cohesion and viscosity after extrusion. In addition, studies have shown that nanomaterials can accelerate the hydration process of 3DPC, improve early strength, and shorten the setting time of 3DPC (Chen Y. et al., 2019; Mendoza Reales et al., 2019; Chen et al., 2020). The fluidity and shape stability of 3DPC can be tuned by adding mineral additives and nanomaterials to 3DPC (Kawashima et al., 2012; Reiter et al., 2018; Qian et al., 2019).

Studies have shown that SWCNT can accelerate the hydration reaction of $\mathrm{C}_{3} \mathrm{~S}$ and strongly impact the morphology of hydration products (Makar and Chan, 2009). The classical reinforcement behaviors observed in their study, such as crack bridging and fiber drawing, and the strong adhesion between C-S-H and CNT, suggest that CNT has a high potential for developing highstrength cementitious composites. SWCNT reinforced cementitious materials exhibit significant enhancements, including 35\% tensile strength, toughness, and significantly improved composite ductility (Mendoza Reales and Dias Toledo Filho, 2017; Rashad, 2017).

MWCNT reinforced cement has higher strength properties (Musso et al., 2009; de Souza et al., 2020). Cement-based nanocomposites were prepared using $0.038 \mathrm{wt} \%$, and $0.08 \mathrm{wt} \%$ of $9.5 \mathrm{~nm}$ functionalized multi-walled carbon nanotube. They found that MWCNT significantly improved Young's modulus, flexural strength, and fracture energy of cement-based materials (Zou et al., 2015). The influence of different lengths of MWCNT on the performance of cement-based materials was investigated. Similarly, the improved flexural strength and elastic modulus of MWCNT modified cement after curing for 3, 7, and 28 days were also investigated. At present, CNT reinforced cement-based materials mainly include: CNTs filling the pores of the matrix (Chaipanich et al., 2010), CNT bridge microcracks in the matrix, and CNTs promoting the growth of C-S-H through nucleation (Alizadeh et al., 2009; Cui et al., 2015; Petrunin et al., 2015; Sikora et al., 2019). These mechanisms could improve the durability of cementitious materials.

CNT is expected to become a potential 3DPC material. Using $\mathrm{CNT}$ in 3DPC can effectively reduce the setting time of 3DPC and 
improve production efficiency. It can reduce drying shrinkage of 3DPC, improve printing quality, and improve the early strength of 3DPC. Finally, it can fill the pores of 3DPC, enhance the toughness of 3DPC, and then improve the shape stability after extrusion. However, there is no related research on CNT reinforced 3DPC yet. The main reason is that the domestic 3DP technology is still in the initial stage, and there is no precise specification for the $3 \mathrm{DP}$ process. The production cost of carbon materials is high, and the production process is complicated. These are the factors that restrict the use of CNT to enhance concrete in 3DPC. However, because 3DP can make some detailed designs according to the model, CNT strengthening the 3DPC becomes possible when designing small models.

\section{CHALLENGES AND FUTURE WORK}

CNT reinforced cement-based materials need mature preparation processes, including dispersion process, molding process, and uniform specifications and standards need to be formulated. Mechanical properties and sensory properties of CNT reinforced cement-based materials cannot be considered simultaneously. When the dosage of CNT is low, the conductive network cannot be formed in the matrix, and the electrical and self-sensing properties are easily affected by polarization. CNT is easy to agglomerate in the matrix when the addition of high CNT content and it is not easy to disperse, which increases the porosity and reduces the mechanical properties of the matrix. The matrix and the external environment easily affect the conductive internal network. The mechanism of the external environment affecting the sensing performance is still unclear. Especially for structures used for a long time, durability is also an important factor affecting their sensing performance. The application technology of cementbased materials in structural health monitoring is immature. At present, most of the research on sensing performance and sensing materials in structural health monitoring is still in the laboratory stage. It is urgent to establish a complete evaluation system, including regulating sensor size, preparation process, test method, evaluation method. It is necessary to improve the interaction relationship between perceptual and mechanical properties and establish a complete integrated standard and specification for structural ontology preparation, application, and evaluation.

CNT is expected to become a potential 3DPC material. However, there is no related research on CNT reinforced $3 \mathrm{DPC}$ yet. The main reason is that the domestic 3DP technology is still in the initial stage, and there is no precise specification for the $3 \mathrm{DP}$ process. The production cost of carbon materials is high, and the production process is complicated. These are the factors that restrict the use of CNT to enhance concrete in 3DPC. Using traditional experimental methods, it is impossible to accurately monitor and characterize the impact mechanism, and durability of various factors on the sensing performance of CNT reinforced cement-based materials, as $\mathrm{CNT}$ ranges in size from nanometers to sub-micrometer.
Molecular dynamics (MD) simulations provide an efficient solution to this problem (Lau et al., 2016; Lau et al., 2018; Jian and Lau, 2019). MD can describe the various effects of nanomaterials on mechanical properties, relating macroscopic mechanical properties to microstructure and intermolecular interactions ( $\mathrm{Yu}$ and Lau, 2015; Jian et al., 2020; Jian et al., 2020; Jian and Lau, 2020; Jian et al., 2021; Nie et al., 2021; Chen et al., 2022). MD simulation can study mechanical phenomena at the molecular level that experiments cannot directly obtain, and explore the interaction between carbon nanotube and cement hydration products from the atomic scale, to obtain the law of how CNT enhances cement-based materials during long-term use (Qin et al., 2019; Wang et al., 2019; Qin et al., 2021; Wang et al., 2021).

Additionally, one of the issues that need to be addressed in 3DPC is the lack of stability and eccentricity (Liu et al., 2022). To improve the interlayer bond strength and solve the problems of stability and eccentricity, CNT reinforced cement-based materials are ideal for printing between two consecutive layers of concrete. The enhanced shape stability of CNT nanomaterialenhanced cement pastes is mainly due to the strong interfacial interaction between $\mathrm{CNT}$ and cement pastes. The interfacial interaction restricts the migration of cement particles to the low shear zone under shearing action, which increases viscosity and elastic shear modulus of the cement paste at the macroscopic scale. However, since the detailed characteristics of the interfacial interaction between $\mathrm{CNT}$ and cement pastes cannot be obtained only from the macroscopic point of view, the basic understanding of their enhancement mechanism is still unclear. It is hoped that the enhancement mechanism of CNT with higher stability and durability in cement pastes can be revealed from the atomic scale (Liu et al., 2022).

MD simulation can simulate the interaction between various factors and the sensing property of CNT enhanced cement-based materials by establishing a correct force field model (Chen et al., 2022). This molecular-scale information help understand the sensing mechanism and the mechanism of the durability of CNT. The success of MD simulations depends mainly on two aspects: the model chosen to represent the material system under study and the force field that simulates atomic interactions (Jian et al., 2021). In terms of force field selection, there is currently no suitable and proven force field to describe the interaction between various factors and CNT reinforced cement-based materials. It is hoped that an accurate force field can be developed.

\section{CONCLUSION}

Compared with ordinary concrete, $\mathrm{CNT}$ reinforced cement-based materials have the advantages of excellent mechanical properties, high sensing sensitivity, good durability, and good compatibility with the matrix. CNT has a broad application prospect in cementbased composites. In this study, we summarize the research progress of CNT in the functional application of building materials. First, the commonly used techniques for the dispersion characterization of CNT are introduced, and the advantages and disadvantages of these techniques are 
summarized. Then, the effects of different influencing factors on the functional application of CNT in cement-based materials were discussed. The functional applications of CNT in cementbased materials were reviewed, including sensing performance, intelligent monitoring of concrete health, and electromagnetic shielding. In addition, the application and development prospects of CNT in 3D printing concrete have also prospected. CNT is expected to become a potential 3DPC material. Using CNT in $3 \mathrm{DPC}$ can effectively reduce the setting time of 3DPC and improve production efficiency; it can reduce drying shrinkage of 3DPC, improve printing quality, and improve the early strength of 3DPC. Finally, the challenges faced in developing and applying CNT reinforced cementitious composites are summarized. Although much research has been done in this field over the past few decades, many questions still need to be addressed. CNT reinforced cement-based materials have good self-sensing properties; it can develop functional materials in related fields. It can be used in national defense, military, earthquake prevention, and disaster reduction. However, at present, related research is in its infancy worldwide, and further research is needed in both theory and practice.

Although we have done lots of research about the CNT reinforced cement-based materials, the research is focused on mechanical properties, the research about durability and intelligent performance is limited, and it is challenging to infer specific laws. In addition, the environmental and health effects of CNT reinforced cement-based materials have also been limitedly investigated. Existing studies on CNT reinforced cement-based materials' performance, deformation, and durability mainly focus on macroscopic properties. There is little research on the micronano structure of CNT reinforced cement-based materials, such as the micro-nano mechanical properties and interface studies. With the development of modern testing technology, nanoindentation, atomic force microscopy, molecular dynamics, and other methods have gradually matured, and new characterization methods have emerged, providing

\section{REFERENCES}

Al-Dahawi, A., Öztürk, O., Emami, F., Yıldırım, G., and Şahmaran, M. (2016a). Effect of Mixing Methods on the Electrical Properties of Cementitious Composites Incorporating Different Carbon-Based Materials. Construction Building Mater. 104, 160-168. doi:10.1016/j. conbuildmat.2015.12.072

Al-Dahawi, A., Sarwary, M. H., Öztürk, O., Yıldırım, G., Akın, G., Şahmaran, M., et al. (2016b). Electrical Percolation Threshold of Cementitious Composites Possessing Self-Sensing Functionality Incorporating Different Carbon-Based Materials. Smart Mater. Struct. 25, 105005. doi:10.1088/0964-1726/25/10/ 105005

Al-Dahawi, A., Yıldırım, G., Öztürk, O., and Şahmaran, M. (2017). Assessment of Self-Sensing Capability of Engineered Cementitious Composites within the Elastic and Plastic Ranges of Cyclic Flexural Loading. Construction Building Mater. 145, 1-10. doi:10.1016/j.conbuildmat.2017.03.236

Al-Qutaifi, S., Nazari, A., and Bagheri, A. (2018). Mechanical Properties of Layered Geopolymer Structures Applicable in concrete 3D-Printing. Construction Building Mater. 176, 690-699. doi:10.1016/j.conbuildmat.2018.04.195

Alizadeh, R., Raki, L., Makar, J. M., Beaudoin, J. J., and Moudrakovski, I. (2009). Hydration of Tricalcium Silicate in the Presence of Synthetic Calcium-SilicateHydrate. J. Mater. Chem. 19, 7937. doi:10.1039/b910216g support for the in-depth study of CNT reinforced cementbased materials. MD simulations help to reveal microscopic physical and chemical processes underlying macroscopic material phenomena. A better understanding of micro-and nanoscale interactions between carbon nanotubes and cementbased materials could help develop better-performing composites. Combining nanoscale MD simulations with macroscale finite element methods is beneficial to study its properties comprehensively. It can bring the advantages of the nanoscale to the macroscale. By establishing unified standards and specifications for CNT reinforced cement-based materials, improving the structure's safety, availability, reliability, and durability, developing cementitious composites with high performance, versatility, and intelligence. As a new generation of building materials, CNT will promote the sustainable development of concrete materials and structures.

\section{AUTHOR CONTRIBUTIONS}

KC: methodology, investigation, writing - original draft. JC: supervision, writing - review and editing LF: writing - review and editing CC: funding acquisition, project administration, writing - review and editing. DL: funding acquisition, project administration, conceptualization, supervision, writing - review and editing.

\section{FUNDING}

The authors are grateful to the support from the Research Grants Council (RGC) of the Hong Kong Special Administrative Region, China, with the Project No. CityU11209418, as well as the supports from National Natural Science Foundation of China (52172015) and The Fundamental Research Funds for the Central Universities in China (DUT21ZD201).

Asprone, D., Menna, C., Bos, F. P., Salet, T. A. M., Mata-Falcón, J., and Kaufmann, W. (2018). Rethinking Reinforcement for Digital Fabrication with concrete. Cement Concrete Res. 112, 111-121. doi:10.1016/j.cemconres.2018.05.020

Assi, L., Alsalman, A., Bianco, D., Ziehl, P., El-Khatib, J., Bayat, M., et al. (2021). Multiwall Carbon Nanotubes (MWCNTs) Dispersion \& Mechanical Effects in OPC Mortar \& Paste: A Review. J. Building Eng. 43, 102512. doi:10.1016/j.jobe. 2021.102512

Azhari, F., and Banthia, N. (2012). Cement-based Sensors with Carbon Fibers and Carbon Nanotubes for Piezoresistive Sensing. Cement and Concrete Composites 34, 866-873. doi:10.1016/j.cemconcomp.2012.04.007

Baeza, F., Galao, O., Zornoza, E., and Garcés, P. (2013). Multifunctional Cement Composites Strain and Damage Sensors Applied on Reinforced concrete (RC) Structural Elements. Materials 6, 841-855. doi:10.3390/ma6030841

Baloch, W. L., Khushnood, R. A., Memon, S. A., Ahmed, W., and Ahmad, S. (2018). Effect of Elevated Temperatures on Mechanical Performance of normal and Lightweight Concretes Reinforced with Carbon Nanotubes. Fire Technol. 54, 1331-1367. doi:10.1007/s10694-018-0733-Z

Birgin, H. B., D’Alessandro, A., Laflamme, S., and Ubertini, F. (2020). Smart Graphite-Cement Composite for Roadway-Integrated Weigh-In-Motion Sensing. Sensors 20, 4518. doi:10.3390/s20164518

Buswell, R. A., Leal De Silva, W. R., Jones, S. Z., and Dirrenberger, J. (2018). 3D Printing Using concrete Extrusion: A Roadmap for Research. Cement Concrete Res. 112, 37-49. doi:10.1016/j.cemconres.2018.05.006 
Chaipanich, A., Nochaiya, T., Wongkeo, W., and Torkittikul, P. (2010). Compressive Strength and Microstructure of Carbon Nanotubes-Fly Ash Cement Composites. Mater. Sci. Eng. A 527, 1063-1067. doi:10.1016/j.msea. 2009.09.039

Chang, J., Cui, K., and Zhang, Y. (2020). Effect of Hybrid Steel Fibers on the Mechanical Performances and Microstructure of Sulphoaluminate CementBased Reactive Powder concrete. Construction Building Mater. 261, 120502. doi:10.1016/j.conbuildmat.2020.120502

Chen, H., Chow, C. L., and Lau, D. (2022). Deterioration Mechanisms and Advanced Inspection Technologies of Aluminum Windows. Materials 15, 354. doi:10.3390/ma15010354

Chen, J., and Akono, A.-T. (2020). Influence of Multi-Walled Carbon Nanotubes on the Hydration Products of Ordinary Portland Cement Paste. Cement Concrete Res. 137, 106197. doi:10.1016/j.cemconres.2020.106197

Chen, J., Qiu, Q., Han, Y., and Lau, D. (2019a). Piezoelectric Materials for Sustainable Building Structures: Fundamentals and Applications. Renew. Sustainable Energ. Rev. 101, 14-25. doi:10.1016/j.rser.2018.09.038

Chen, Y., Chaves Figueiredo, S., Yalçinkaya, Ç., Çopuroğlu, O., Veer, F., and Schlangen, E. (2019b). The Effect of Viscosity-Modifying Admixture on the Extrudability of limestone and Calcined Clay-Based Cementitious Material for Extrusion-Based 3D concrete Printing. Materials 12, 1374. doi:10.3390/ ma12091374

Chen, Y., Romero Rodriguez, C., Li, Z., Chen, B., Çopuroğlu, O., and Schlangen, E. (2020). Effect of Different Grade Levels of Calcined Clays on Fresh and Hardened Properties of Ternary-Blended Cementitious Materials for 3D Printing. Cement and Concrete Composites 114, 103708. doi:10.1016/j. cemconcomp.2020.103708

Cui, H., Yang, S., and Memon, S. (2015). Development of Carbon Nanotube Modified Cement Paste with Microencapsulated Phase-Change Material for Structural-Functional Integrated Application. Ijms 16, 8027-8039. doi:10.3390/ ijms 16048027

Cui, K., Lau, D., Zhang, Y., and Chang, J. (2021). Mechanical Properties and Mechanism of Nano-CaCO3 Enhanced Sulphoaluminate Cement-Based Reactive Powder concrete. Construction Building Mater. 309, 125099. doi:10. 1016/j.conbuildmat.2021.125099

D’Alessandro, A., Tiecco, M., Meoni, A., and Ubertini, F. (2021). Improved Strain Sensing Properties of Cement-Based Sensors through Enhanced Carbon Nanotube Dispersion. Cement and Concrete Composites 115, 103842. doi:10. 1016/j.cemconcomp.2020.103842

D’Alessandro, A., Ubertini, F., García-Macías, E., Castro-Triguero, R., Downey, A., Laflamme, S., et al. (20172017). Static and Dynamic Strain Monitoring of Reinforced concrete Components through Embedded Carbon Nanotube Cement-Based Sensors. Shock and Vibration 2017, 1-11. doi:10.1155/2017/ 3648403

D’Alessandro, A., Ubertini, F., Materazzi, A. L., Laflamme, S., and Porfiri, M. (2015). Electromechanical Modelling of a New Class of Nanocomposite Cement-Based Sensors for Structural Health Monitoring. Struct. Health Monit. 14, 137-147. doi:10.1177/1475921714560071

Datsyuk, V., Kalyva, M., Papagelis, K., Parthenios, J., Tasis, D., Siokou, A., et al. (2008). Chemical Oxidation of Multiwalled Carbon Nanotubes. Carbon 46, 833-840. doi:10.1016/j.carbon.2008.02.012

de Souza, T. C., Pinto, G., Cruz, V. S., Moura, M., Ladeira, L. O., and Calixto, J. M. (2020). Evaluation of the Rheological Behavior, Hydration Process, and Mechanical Strength of Portland Cement Pastes Produced with Carbon Nanotubes Synthesized Directly on Clinker. Construction Building Mater. 248, 118686. doi:10.1016/j.conbuildmat.2020.118686

Demircilioglu, E., Teomete, E., and Ozbulut, O. E. (2020). Strain Sensitivity of Steel-Fiber-Reinforced Industrial Smart concrete. J. Intell. Mater. Syst. Structures 31, 127-136. doi:10.1177/1045389X19888722

Demircilioğlu, E., Teomete, E., Schlangen, E., and Baeza, F. J. (2019). Temperature and Moisture Effects on Electrical Resistance and Strain Sensitivity of Smart concrete. Construction Building Mater. 224, 420-427. doi:10.1016/j. conbuildmat.2019.07.091

Ding, S., Wang, Y.-W., Ni, Y.-Q., and Han, B. (2020). Structural Modal Identification and Health Monitoring of Building Structures Using SelfSensing Cementitious Composites. Smart Mater. Struct. 29, 055013. doi:10. 1088/1361-665X/ab79b9
Eftekhari, M., Hatefi Ardakani, S., and Mohammadi, S. (2014). An XFEM Multiscale Approach for Fracture Analysis of Carbon Nanotube Reinforced concrete. Theor. Appl. Fracture Mech. 72, 64-75. doi:10.1016/j.tafmec.2014. 06.005

Eftekhari, M., Karrech, A., and Elchalakani, M. (2020). Investigation into the Nonlinear Time-History Analysis of CNT-Reinforced concrete Column by a Multiscale Approach. Int. J. Civ Eng. 18, 49-64. doi:10.1007/s40999-01900459-6

Elkashef, M., Wang, K., and Abou-Zeid, M. N. (2016). Acid-treated Carbon Nanotubes and Their Effects on Mortar Strength. Front. Struct. Civ. Eng. 10, 180-188. doi:10.1007/s11709-015-0325-7

Feng, P., Meng, X., Chen, J.-F., and Ye, L. (2015). Mechanical Properties of Structures 3D Printed with Cementitious Powders. Construction Building Mater. 93, 486-497. doi:10.1016/j.conbuildmat.2015.05.132

Galao, O., Baeza, F. J., Zornoza, E., and Garcés, P. (2014). Strain and Damage Sensing Properties on Multifunctional Cement Composites with CNF Admixture. Cement and Concrete Composites 46, 90-98. doi:10.1016/j. cemconcomp.2013.11.009

García-Macías, E., Downey, A., D’Alessandro, A., Castro-Triguero, R., Laflamme, S., and Ubertini, F. (2017). Enhanced Lumped Circuit Model for Smart Nanocomposite Cement-Based Sensors under Dynamic Compressive Loading Conditions. Sensors Actuators A: Phys. 260, 45-57. doi:10.1016/j. sna.2017.04.004

Gibbons, G. J., Williams, R., Purnell, P., and Farahi, E. (2010). 3D Printing of Cement Composites. Adv. Appl. Ceramics 109, 287-290. doi:10.1179/ 174367509 X12472364600878

Gosselin, C., Duballet, R., Roux, P., Gaudillière, N., Dirrenberger, J., and Morel, P. (2016). Large-scale 3D Printing of Ultra-high Performance concrete - a New Processing Route for Architects and Builders. Mater. Des. 100, 102-109. doi:10. 1016/j.matdes.2016.03.097

Grayson, J. K. (1996). Radiation Exposure, Socioeconomic Status, and Brain Tumor Risk in the US Air Force: A Nested Case-Control Study. Am. J. Epidemiol. 143, 480-486. doi:10.1093/oxfordjournals.aje.a008768

Gupta, S., Gonzalez, J. G., and Loh, K. J. (2017). Self-sensing concrete Enabled by Nano-Engineered Cement-Aggregate Interfaces. Struct. Health Monit. 16, 309-323. doi:10.1177/1475921716643867

Hambach, M., and Volkmer, D. (2017). Properties of 3D-Printed Fiber-Reinforced Portland Cement Paste. Cement and Concrete Composites 79, 62-70. doi:10. 1016/j.cemconcomp.2017.02.001

Han, J., Pan, J., Cai, J., and Li, X. (2020). A Review on Carbon-Based Self-Sensing Cementitious Composites. Construction Building Mater. 265, 120764. doi:10. 1016/j.conbuildmat.2020.120764

Hosseini, P., Hosseinpourpia, R., Pajum, A., Khodavirdi, M. M., Izadi, H., and Vaezi, A. (2014). Effect of Nano-Particles and Aminosilane Interaction on the Performances of Cement-Based Composites: An Experimental Study. Construction Building Mater. 66, 113-124. doi:10.1016/j.conbuildmat.2014. 05.047

Jian, W., Hui, D., and Lau, D. (2020). Nanoengineering in Biomedicine: Current Development and Future Perspectives. Nanotechnology Rev. 9, 700-715. doi:10. 1515/ntrev-2020-0053

Jian, W., and Lau, D. (2019). Creep Performance of CNT-Based Nanocomposites: A Parametric Study. Carbon 153, 745-756. doi:10.1016/j.carbon.2019.07.069

Jian, W., and Lau, D. (2020). Understanding the Effect of Functionalization in CNT-Epoxy Nanocomposite from Molecular Level. Composites Sci. Technology 191, 108076. doi:10.1016/j.compscitech.2020.108076

Jian, W., Wang, X., Lu, H., and Lau, D. (2021). Molecular Dynamics Simulations of Thermodynamics and Shape Memory Effect in CNT-Epoxy Nanocomposites. Composites Sci. Technology 211, 108849. doi:10.1016/j.compscitech.2021. 108849

Jing, G., Siahkouhi, M., Riley Edwards, J., Dersch, M. S., and Hoult, N. A. (2021). Smart Railway Sleepers - a Review of Recent Developments, Challenges, and Future Prospects. Construction Building Mater. 271, 121533. doi:10.1016/j. conbuildmat.2020.121533

Jung, M., Lee, Y.-s., Hong, S.-G., and Moon, J. (2020a). Carbon Nanotubes (CNTs) in Ultra-high Performance concrete (UHPC): Dispersion, Mechanical Properties, and Electromagnetic Interference (EMI) Shielding Effectiveness (SE). Cement Concrete Res. 131, 106017. doi:10.1016/j.cemconres.2020.106017 
Jung, M., Park, J., Hong, S.-g., and Moon, J. (2020b). Electrically Cured Ultra-high Performance concrete (UHPC) Embedded with Carbon Nanotubes for Field Casting and Crack Sensing. Mater. Des. 196, 109127. doi:10.1016/j.matdes. 2020.109127

Kawashima, S., Kim, J. H., Corr, D. J., and Shah, S. P. (2012). Study of the Mechanisms Underlying the Fresh-State Response of Cementitious Materials Modified with Nanoclays. Construction Building Mater. 36, 749-757. doi:10. 1016/j.conbuildmat.2012.06.057

Kazemian, A., Yuan, X., Cochran, E., and Khoshnevis, B. (2017). Cementitious Materials for Construction-Scale 3D Printing: Laboratory Testing of Fresh Printing Mixture. Construction Building Mater. 145, 639-647. doi:10.1016/j. conbuildmat.2017.04.015

Khan, M. A. (2020). Mix Suitable for concrete 3D Printing: A Review. Mater. Today Proc. 32, 831-837. doi:10.1016/j.matpr.2020.03.825

Kim, G. M., Naeem, F., Kim, H. K., and Lee, H. K. (2016). Heating and Heatdependent Mechanical Characteristics of CNT-Embedded Cementitious Composites. Compos. Structures 136, 162-170. doi:10.1016/j.compstruct. 2015.10.010

Kim, G. M., Park, S. M., Ryu, G. U., and Lee, H. K. (2017a). Electrical Characteristics of Hierarchical Conductive Pathways in Cementitious Composites Incorporating $\mathrm{CNT}$ and Carbon Fiber. Cement and Concrete Composites 82, 165-175. doi:10.1016/j.cemconcomp.2017.06.004

Kim, G. M., Yang, B. J., Cho, K. J., Kim, E. M., and Lee, H. K. (2017b). Influences of CNT Dispersion and Pore Characteristics on the Electrical Performance of Cementitious Composites. Compos. Structures 164, 32-42. doi:10.1016/j. compstruct.2016.12.049

Kim, H. K., Nam, I. W., and Lee, H. K. (2014a). Enhanced Effect of Carbon Nanotube on Mechanical and Electrical Properties of Cement Composites by Incorporation of Silica Fume. Compos. Structures 107, 60-69. doi:10.1016/j. compstruct.2013.07.042

Kim, H. K., Park, I. S., and Lee, H. K. (2014b). Improved Piezoresistive Sensitivity and Stability of CNT/cement Mortar Composites with Low Water-Binder Ratio. Compos. Structures 116, 713-719. doi:10.1016/j.compstruct.2014.06.007

Konsta-Gdoutos, M. S., and Aza, C. A. (2014). Self Sensing Carbon Nanotube (CNT) and Nanofiber (CNF) Cementitious Composites for Real Time Damage Assessment in Smart Structures. Cement and Concrete Composites 53, 162-169. doi:10.1016/j.cemconcomp.2014.07.003

Konsta-Gdoutos, M. S., Metaxa, Z. S., and Shah, S. P. (2010). Highly Dispersed Carbon Nanotube Reinforced Cement Based Materials. Cement Concrete Res. 40, 1052-1059. doi:10.1016/j.cemconres.2010.02.015

Lau, D., Jian, W., Yu, Z., and Hui, D. (2018). Nano-engineering of Construction Materials Using Molecular Dynamics Simulations: Prospects and Challenges. Composites B: Eng. 143, 282-291. doi:10. 1016/j.compositesb.2018.01.014

Lau, D., Qiu, Q., Zhou, A., and Chow, C. L. (2016). Long Term Performance and Fire Safety Aspect of FRP Composites Used in Building Structures. Construction Building Mater. 126, 573-585. doi:10.1016/j.conbuildmat.2016.09.031

Le, H. V., and Kim, D. J. (2020). Detecting Crack and Damage Location in SelfSensing Fiber Reinforced Cementitious Composites. Construction Building Mater. 240, 117973. doi:10.1016/j.conbuildmat.2019.117973

Le, H. V., and Kim, D. J. (2017). Effect of Matrix Cracking on Electrical Resistivity of High Performance Fiber Reinforced Cementitious Composites in Tension. Construction Building Mater. 156, 750-760. doi:10.1016/j.conbuildmat.2017. 09.046

Le, T. T., Austin, S. A., Lim, S., Buswell, R. A., Gibb, A. G. F., and Thorpe, T. (2012a). Mix Design and Fresh Properties for High-Performance Printing concrete. Mater. Struct. 45, 1221-1232. doi:10.1617/s11527-012-9828-Z

Le, T. T., Austin, S. A., Lim, S., Buswell, R. A., Law, R., Gibb, A. G. F., et al. (2012b). Hardened Properties of High-Performance Printing concrete. Cement Concrete Res. 42, 558-566. doi:10.1016/j.cemconres.2011.12.003

Lee, H., Yu, W., Loh, K. J., and Chung, W. (2020). Self-heating and Electrical Performance of Carbon Nanotube-Enhanced Cement Composites. Construction Building Mater. 250, 118838. doi:10.1016/j.conbuildmat.2020. 118838

Li, G. Y., Wang, P. M., and Zhao, X. (2005). Mechanical Behavior and Microstructure of Cement Composites Incorporating Surface-Treated MultiWalled Carbon Nanotubes. Carbon 43, 1239-1245. doi:10.1016/j.carbon.2004. 12.017
Li, Y., Li, H., Wang, Z., and Jin, C. (2020). Effect and Mechanism Analysis of Functionalized Multi-Walled Carbon Nanotubes (MWCNTs) on C-S-H Gel. Cement Concrete Res. 128, 105955. doi:10.1016/j.cemconres.2019.105955

Liu, J., Jian, W., and Lau, D. (2022). Boron Nitride Nanosheet as a Promising Reinforcement for Cementitious Composites. Appl. Surf. Sci. 572, 151395. doi:10.1016/j.apsusc.2021.151395

Liu, Z., Zhang, Y., Liu, L., and Jiang, Q. (2013). An Analytical Model for Determining the Relative Electrical Resistivity of Cement Paste and C-S-H Gel. Construction Building Mater. 48, 647-655. doi:10.1016/j.conbuildmat. 2013.07.020

Ma, G., Li, Z., and Wang, L. (2018a). Printable Properties of Cementitious Material Containing Copper Tailings for Extrusion Based 3D Printing. Construction Building Mater. 162, 613-627. doi:10.1016/j.conbuildmat.2017.12.051

Ma, G., and Wang, L. (2018). A Critical Review of Preparation Design and Workability Measurement of concrete Material for Largescale 3D Printing. Front. Struct. Civ. Eng. 12, 382-400. doi:10.1007/s11709-017-0430-x

Ma, G., Wang, L., and Ju, Y. (2018b). State-of-the-art of 3D Printing Technology of Cementitious Material-An Emerging Technique for Construction. Sci. China Technol. Sci. 61, 475-495. doi:10.1007/s11431-016-9077-7

MacLeod, A. J. N., Collins, F. G., and Duan, W. (2021). Effects of Carbon Nanotubes on the Early-Age Hydration Kinetics of Portland Cement Using Isothermal Calorimetry. Cement and Concrete Composites 119, 103994. doi:10. 1016/j.cemconcomp.2021.103994

Makar, J. M., and Chan, G. W. (2009). Growth of Cement Hydration Products on Single-Walled Carbon Nanotubes. J. Am. Ceram. Soc. 92, 1303-1310. doi:10. 1111/j.1551-2916.2009.03055.x

Malekzadeh, P., and Zarei, A. R. (2014). Free Vibration of Quadrilateral Laminated Plates with Carbon Nanotube Reinforced Composite Layers. Thin-Walled Structures 82, 221-232. doi:10.1016/j.tws.2014.04.016

Materazzi, A. L., Ubertini, F., and D’Alessandro, A. (2013). Carbon Nanotube Cement-Based Transducers for Dynamic Sensing of Strain. Cement and Concrete Composites 37, 2-11. doi:10.1016/j.cemconcomp.2012.12.013

Mendoza, O., Sierra, G., and Tobón, J. I. (2014). Effect of the Reagglomeration Process of Multi-Walled Carbon Nanotubes Dispersions on the Early Activity of Nanosilica in Cement Composites. Construction Building Mater. 54, 550-557. doi:10.1016/j.conbuildmat.2013.12.084

Mendoza Reales, O. A., and Dias Toledo Filho, R. (2017). A Review on the Chemical, Mechanical and Microstructural Characterization of Carbon Nanotubes-Cement Based Composites. Construction Building Mater. 154, 697-710. doi:10.1016/j.conbuildmat.2017.07.232

Mendoza Reales, O. A., Duda, P., Silva, E. C. C. M., Paiva, M. D. M., and Filho, R. D. T. (2019). Nanosilica Particles as Structural Buildup Agents for 3D Printing with Portland Cement Pastes. Construction Building Mater. 219, 91-100. doi:10.1016/j.conbuildmat.2019.05.174

Micheli, D., Pastore, R., Vricella, A., Morles, R. B., Marchetti, M., Delfini, A., et al. (2014). Electromagnetic Characterization and Shielding Effectiveness of concrete Composite Reinforced with Carbon Nanotubes in the mobile Phones Frequency Band. Mater. Sci. Eng. B 188, 119-129. doi:10.1016/j. mseb.2014.07.001

Monteiro, A. O., Loredo, A., Costa, P. M. F. J., Oeser, M., and Cachim, P. B. (2017). A Pressure-Sensitive Carbon Black Cement Composite for Traffic Monitoring. Construction Building Mater. 154, 1079-1086. doi:10.1016/j.conbuildmat.2017. 08.053

Musso, S., Tulliani, J.-M., Ferro, G., and Tagliaferro, A. (2009). Influence of Carbon Nanotubes Structure on the Mechanical Behavior of Cement Composites. Composites Sci. Technology 69, 1985-1990. doi:10.1016/j.compscitech.2009. 05.002

Nam, I. W., Choi, J. H., Kim, C. G., and Lee, H. K. (2018). Fabrication and Design of Electromagnetic Wave Absorber Composed of Carbon Nanotube-Incorporated Cement Composites. Compos. Structures 206, 439-447. doi:10.1016/j. compstruct.2018.07.058

Nam, I. W., Lee, H. K., and Jang, J. H. (2011). Electromagnetic Interference Shielding/absorbing Characteristics of CNT-Embedded Epoxy Composites. Composites A: Appl. Sci. Manufacturing 42, 1110-1118. doi:10.1016/j. compositesa.2011.04.016

Nam, I. W., Souri, H., and Lee, H. K. (2016). Percolation Threshold and Piezoresistive Response of Multi-wall Carbon Nanotube/cement Composites. Smart Structures Syst. 18, 217-231. doi:10.12989/sss.2016.18.2.217 
Ngo, T. D., Kashani, A., Imbalzano, G., Nguyen, K. T. Q., and Hui, D. (2018). Additive Manufacturing (3D Printing): A Review of Materials, Methods, Applications and Challenges. Composites Part B: Eng. 143, 172-196. doi:10. 1016/j.compositesb.2018.02.012

Nie, F., Jian, W., and Lau, D. (2021). An Atomistic Study on the Thermomechanical Properties of Graphene and Functionalized Graphene Sheets Modified Asphalt. Carbon 182, 615-627. doi:10.1016/j.carbon.2021. 06.055

Noorvand, H., Ali, A. A. A., Demirboga, R., Noorvand, H., and Farzadnia, N. (2013). Physical and Chemical Characteristics of Unground palm Oil Fuel Ash Cement Mortars with Nanosilica. Construction Building Mater. 48, 1104-1113. doi:10.1016/j.conbuildmat.2013.07.070

Panda, B., Chandra Paul, S., and Jen Tan, M. (2017a). Anisotropic Mechanical Performance of 3D Printed Fiber Reinforced Sustainable Construction Material. Mater. Lett. 209, 146-149. doi:10.1016/j.matlet.2017.07.123

Panda, B., Paul, S. C., Hui, L. J., Tay, Y. W. D., and Tan, M. J. (2017b). Additive Manufacturing of Geopolymer for Sustainable Built Environment. J. Clean. Prod. 167, 281-288. doi:10.1016/j.jclepro.2017.08.165

Panda, B., Paul, S. C., Mohamed, N. A. N., Tay, Y. W. D., and Tan, M. J. (2018). Measurement of Tensile Bond Strength of 3D Printed Geopolymer Mortar. Measurement 113, 108-116. doi:10.1016/j.measurement.2017.08.051

Panda, B., Ruan, S., Unluer, C., and Tan, M. J. (2019). Improving the 3D Printability of High Volume Fly Ash Mixtures via the Use of Nano Attapulgite clay. Composites Part B: Eng. 165, 75-83. doi:10.1016/j. compositesb.2018.11.109

Perrot, A., Rangeard, D., and Pierre, A. (2016). Structural Built-Up of CementBased Materials Used for 3D-Printing Extrusion Techniques. Mater. Struct. 49, 1213-1220. doi:10.1617/s11527-015-0571-0

Petrunin, S., Vaganov, V., Reshetniak, V., and Zakrevskaya, L. (2015). Influence of Carbon Nanotubes on the Structure Formation of Cement Matrix. IOP Conf. Ser. Mater. Sci. Eng. 96, 012046. doi:10.1088/1757-899X/ 96/1/012046

Qian, Y., Ma, S., Kawashima, S., and De Schutter, G. (2019). Rheological Characterization of the Viscoelastic Solid-like Properties of Fresh Cement Pastes with Nanoclay Addition. Theor. Appl. Fracture Mech. 103, 102262. doi:10.1016/j.tafmec.2019.102262

Qin, R., Hao, H., Rousakis, T., and Lau, D. (2019). Effect of Shrinkage Reducing Admixture on New-To-Old concrete Interface. Composites Part B: Eng. 167, 346-355. doi:10.1016/j.compositesb.2018.11.087

Qin, R., Zhou, A., Yu, Z., Wang, Q., and Lau, D. (2021). Role of Carbon Nanotube in Reinforcing Cementitious Materials: An Experimental and Coarse-Grained Molecular Dynamics Study. Cement Concrete Res. 147, 106517. doi:10.1016/j. cemconres.2021.106517

Ramezani, M., Dehghani, A., and Sherif, M. M. (2022). Carbon Nanotube Reinforced Cementitious Composites: A Comprehensive Review. Construction Building Mater. 315, 125100. doi:10.1016/j.conbuildmat.2021. 125100

Rashad, A. M. (2017). Effect of Carbon Nanotubes (CNTs) on the Properties of Traditional Cementitious Materials. Construction Building Mater. 153, 81-101. doi:10.1016/j.conbuildmat.2017.07.089

Reiter, L., Wangler, T., Roussel, N., and Flatt, R. J. (2018). The Role of Early Age Structural Build-Up in Digital Fabrication with concrete. Cement Concrete Res. 112, 86-95. doi:10.1016/j.cemconres.2018.05.011

Sasmal, S., Ravivarman, N., Sindu, B. S., and Vignesh, K. (2017). Electrical Conductivity and Piezo-Resistive Characteristics of CNT and CNF Incorporated Cementitious Nanocomposites under Static and Dynamic Loading. Composites Part a: Appl. Sci. Manufacturing 100, 227-243. doi:10. 1016/j.compositesa.2017.05.018

Seol, Y.-J., Kang, H.-W., Lee, S. J., Atala, A., and Yoo, J. J. (2014). Bioprinting Technology and its Applications. Eur. J. Cardio-Thoracic Surg. 46, 342-348. doi:10.1093/ejcts/ezu148

Sethi, J., Sarlin, E., Meysami, S. S., Suihkonen, R., Santha Kumar, A. R. S., Honkanen, M., et al. (2017). The Effect of Multi-wall Carbon Nanotube Morphology on Electrical and Mechanical Properties of Polyurethane Nanocomposites. Composites Part a: Appl. Sci. Manufacturing 102, 305-313. doi:10.1016/j.compositesa.2017.08.014

Sheikh, T. M., Anwar, M. P., Muthoosamy, K., Jaganathan, J., Chan, A., and Mohamed, A. A. (2021). The Mechanics of Carbon-Based Nanomaterials as
Cement Reinforcement - A Critical Review. Construction Building Mater. 303, 124441. doi:10.1016/j.conbuildmat.2021.124441

Shi, T., Li, Z., Guo, J., Gong, H., and Gu, C. (2019). Research Progress on CNTs/ CNFs-Modified Cement-Based Composites - A Review. Construction Building Mater. 202, 290-307. doi:10.1016/j.conbuildmat.2019.01.024

Siad, H., Lachemi, M., Sahmaran, M., Mesbah, H. A., and Hossain, K. A. (2018). Advanced Engineered Cementitious Composites with Combined Self-Sensing and Self-Healing Functionalities. Construction Building Mater. 176, 313-322. doi:10.1016/j.conbuildmat.2018.05.026

Sikora, P., Abd Elrahman, M., Chung, S.-Y., Cendrowski, K., Mijowska, E., and Stephan, D. (2019). Mechanical and Microstructural Properties of Cement Pastes Containing Carbon Nanotubes and Carbon Nanotube-Silica Core-Shell Structures, Exposed to Elevated Temperature. Cement and Concrete Composites 95, 193-204. doi:10.1016/j.cemconcomp.2018.11.006

Sindu, B. S., and Sasmal, S. (2017). Properties of Carbon Nanotube Reinforced Cement Composite Synthesized Using Different Types of Surfactants. Construction Building Mater. 155, 389-399. doi:10.1016/j.conbuildmat.2017. 08.059

Singh, A. P., Gupta, B. K., Mishra, M., Govind, Chandra, A., Mathur, R. B., et al. (2013). Multiwalled Carbon Nanotube/cement Composites with Exceptional Electromagnetic Interference Shielding Properties. Carbon 56, 86-96. doi:10. 1016/j.carbon.2012.12.081

Snelson, D. G., Wild, S., and O'Farrell, M. (2008). Heat of Hydration of Portland Cement-Metakaolin-Fly Ash (PC-MK-PFA) Blends. Cement Concrete Res. 38, 832-840. doi:10.1016/j.cemconres.2008.01.004

Sobolkina, A., Mechtcherine, V., Khavrus, V., Maier, D., Mende, M., Ritschel, M., et al. (2012). Dispersion of Carbon Nanotubes and its Influence on the Mechanical Properties of the Cement Matrix. Cement and Concrete Composites 34, 1104-1113. doi:10.1016/j.cemconcomp.2012.07.008

Soltan, D. G., and Li, V. C. (2018). A Self-Reinforced Cementitious Composite for Building-Scale 3D Printing. Cement and Concrete Composites 90, 1-13. doi:10. 1016/j.cemconcomp.2018.03.017

Sun, J., Zhou, W., Huang, D., Fuh, J. Y. H., and Hong, G. S. (2015). An Overview of 3D Printing Technologies for Food Fabrication. Food Bioproc. Technol 8, 1605-1615. doi:10.1007/s11947-015-1528-6

Sun, M., Li, Z., and Liu, Q. (2002). The Electromechanical Effect of Carbon Fiber Reinforced Cement. Carbon 40, 2273-2275. doi:10.1016/S0008-6223(02) 00189-6

Szmigielski, S. (1996). Cancer Morbidity in Subjects Occupationally Exposed to High Frequency (Radiofrequency and Microwave) Electromagnetic Radiation. Sci. Total Environ. 180, 9-17. doi:10.1016/0048-9697(95)04915-0

Tay, Y. W. D., Ting, G. H. A., Qian, Y., Panda, B., He, L., and Tan, M. J. (2019). Time gap Effect on Bond Strength of 3D-Printed concrete. Virtual Phys. Prototyping 14, 104-113. doi:10.1080/17452759.2018.1500420

Ubertini, F., Materazzi, A. L., D’Alessandro, A., and Laflamme, S. (2014). Natural Frequencies Identification of a Reinforced concrete Beam Using Carbon Nanotube Cement-Based Sensors. Eng. Structures 60, 265-275. doi:10.1016/j. engstruct.2013.12.036

Vaisman, L., Wagner, H. D., and Marom, G. (2006). The Role of Surfactants in Dispersion of Carbon Nanotubes. Adv. Colloid Interf. Sci. 128-130, 37-46. doi:10.1016/j.cis.2006.11.007

Wanasinghe, D., Aslani, F., Ma, G., and Habibi, D. (2020). Advancements in Electromagnetic Interference Shielding Cementitious Composites. Construction Building Mater. 231, 117116. doi:10.1016/j.conbuildmat.2019.117116

Wang, B., Guo, Z., Han, Y., and Zhang, T. (2013a). Electromagnetic Wave Absorbing Properties of Multi-Walled Carbon Nanotube/cement Composites. Construction Building Mater. 46, 98-103. doi:10.1016/j. conbuildmat.2013.04.006

Wang, B., Han, Y., and Liu, S. (2013b). Effect of Highly Dispersed Carbon Nanotubes on the Flexural Toughness of Cement-Based Composites. Construction Building Mater. 46, 8-12. doi:10.1016/j.conbuildmat.2013.04.014

Wang, X. Q., Chow, C. L., and Lau, D. (2019). A Review on Modeling Techniques of Cementitious Materials under Different Length Scales: Development and Future Prospects. Adv. Theor. Simul. 2, 1900047. doi:10.1002/adts.201900047

Wang, X. Q., Jian, W., Buyukozturk, O., Leung, C. K. Y., and Lau, D. (2021). Degradation of Epoxy/glass Interface in Hygrothermal Environment: An Atomistic Investigation. Composites Part B: Eng. 206, 108534. doi:10.1016/j. compositesb.2020.108534 
Wang, X., Wang, J., Biswas, S., Kim, H., and Nam, I. (2020). Mechanical, Electrical, and Piezoresistive Sensing Characteristics of Epoxy-Based Composites Incorporating Hybridized Networks of Carbon Nanotubes, Graphene, Carbon Nanofibers, or Graphite Nanoplatelets. Sensors 20, 2094. doi:10. 3390/s20072094

Wen, S., and Chung, D. D. L. (2006). The Role of Electronic and Ionic Conduction in the Electrical Conductivity of Carbon Fiber Reinforced Cement. Carbon 44, 2130-2138. doi:10.1016/j.carbon.2006.03.013

Xing, W., Yang, W., Yang, W., Hu, Q., Si, J., Lu, H., et al. (2016). Functionalized Carbon Nanotubes with Phosphorus- and Nitrogen-Containing Agents: Effective Reinforcer for thermal, Mechanical, and Flame-Retardant Properties of Polystyrene Nanocomposites. ACS Appl. Mater. Inter. 8, 26266-26274. doi:10.1021/acsami.6b06864

$\mathrm{Xu}$, S., Liu, J., and Li, Q. (2015). Mechanical Properties and Microstructure of Multi-Walled Carbon Nanotube-Reinforced Cement Paste. Construction Building Mater. 76, 16-23. doi:10.1016/j.conbuildmat.2014.11.049

$\mathrm{Xu}, \mathrm{S}$., Lyu, Y., Xu, S., and Li, Q. (2019). Enhancing the Initial Cracking Fracture Toughness of Steel-Polyvinyl Alcohol Hybrid Fibers Ultra High Toughness Cementitious Composites by Incorporating Multi-Walled Carbon Nanotubes. Construction Building Mater. 195, 269-282. doi:10.1016/j.conbuildmat.2018.10.133

Ye, H., Cartwright, C., Rajabipour, F., and Radlińska, A. (2017). Understanding the Drying Shrinkage Performance of Alkali-Activated Slag Mortars. Cement and Concrete Composites 76, 13-24. doi:10.1016/j.cemconcomp.2016.11.010

Ye, J., Cui, C., Yu, J., Yu, K., and Xiao, J. (2021). Fresh and Anisotropic-Mechanical Properties of 3D Printable Ultra-high Ductile concrete with Crumb Rubber. Composites Part B: Eng. 211, 108639. doi:10.1016/j.compositesb.2021.108639

Yildirim, G., Aras, G. H., Banyhussan, Q. S., Şahmaran, M., and Lachemi, M. (2015). Estimating the Self-Healing Capability of Cementitious Composites through Non-destructive Electrical-Based Monitoring. NDT E Int. 76, 26-37. doi:10.1016/j.ndteint.2015.08.005

Yıldırım, G., Öztürk, O., Al-Dahawi, A., Afşın Ulu, A., and Şahmaran, M. (2020). Self-sensing Capability of Engineered Cementitious Composites: Effects of Aging and Loading Conditions. Construction Building Mater. 231, 117132. doi:10.1016/j.conbuildmat.2019.117132

Yıldırım, G., Sarwary, M. H., Al-Dahawi, A., Öztürk, O., Anıl, Ö., and Şahmaran, M. (2018). Piezoresistive Behavior of CF- and CNT-Based Reinforced concrete Beams Subjected to Static Flexural Loading: Shear Failure Investigation. Construction Building Mater. 168, 266-279. doi:10.1016/j.conbuildmat.2018. 02.124

Yoo, D.-Y., You, I., and Lee, S.-J. (2017). Electrical Properties of Cement-Based Composites with Carbon Nanotubes, Graphene, and Graphite Nanofibers. Sensors 17, 1064. doi:10.3390/s17051064
Yoo, D.-Y., You, I., Zi, G., and Lee, S.-J. (2019). Effects of Carbon Nanomaterial Type and Amount on Self-Sensing Capacity of Cement Paste. Measurement 134, 750-761. doi:10.1016/j.measurement.2018.11.024

Yoon, H. N., Jang, D., Lee, H. K., and Nam, I. W. (2021). Influence of Carbon Fiber Additions on the Electromagnetic Wave Shielding Characteristics of CNTCement Composites. Construction Building Mater. 269, 121238. doi:10.1016/j. conbuildmat.2020.121238

Yu, H., Jin, Y., Peng, F., Wang, H., and Yang, J. (2008). Kinetically Controlled SideWall Functionalization of Carbon Nanotubes by Nitric Acid Oxidation. J. Phys. Chem. C 112, 6758-6763. doi:10.1021/jp711975a

Yu, S., Bale, H., Park, S., Hwang, J. Y., and Hong, S. H. (2021). Anisotropic Microstructure Dependent Mechanical Behavior of 3D-Printed basalt FiberReinforced Thermoplastic Composites. Composites Part B: Eng. 224, 109184. doi:10.1016/j.compositesb.2021.109184

Yu, Z., and Lau, D. (2015). Nano- and Mesoscale Modeling of Cement Matrix. Nanoscale Res. Lett. 10. doi:10.1186/s11671-015-0862-y

Zhou, Z., Xie, N., Cheng, X., Feng, L., Hou, P., Huang, S., et al. (2020). Electrical Properties of Low Dosage Carbon Nanofiber/cement Composite: Percolation Behavior and Polarization Effect. Cement and Concrete Composites 109, 103539. doi:10.1016/j.cemconcomp.2020.103539

Zou, B., Chen, S. J., Korayem, A. H., Collins, F., Wang, C. M., and Duan, W. H. (2015). Effect of Ultrasonication Energy on Engineering Properties of Carbon Nanotube Reinforced Cement Pastes. Carbon 85, 212-220. doi:10.1016/j. carbon.2014.12.094

Conflict of Interest: The authors declare that the research was conducted in the absence of any commercial or financial relationships that could be construed as a potential conflict of interest.

Publisher's Note: All claims expressed in this article are solely those of the authors and do not necessarily represent those of their affiliated organizations, or those of the publisher, the editors and the reviewers. Any product that may be evaluated in this article, or claim that may be made by its manufacturer, is not guaranteed or endorsed by the publisher.

Copyright (c) 2022 Cui, Chang, Feo, Chow and Lau. This is an open-access article distributed under the terms of the Creative Commons Attribution License (CC BY). The use, distribution or reproduction in other forums is permitted, provided the original author(s) and the copyright owner(s) are credited and that the original publication in this journal is cited, in accordance with accepted academic practice. No use, distribution or reproduction is permitted which does not comply with these terms. 